\title{
INDICADORES QUIIMICOS DO SOLO SOB DIFERENTES USOS E MANEJO NO LOTE 31 DO PROJETO DE ASSENTAMENTO VENEZA NO SUDESTE DO PARÁ
}

\author{
Kalyne Rosa da Silva'; Elayne Theresa Oliveira Pontes Amaral2 ; Andressa Nunes de \\ Oliveira ${ }^{3}$; Andrea Hentz de Mello4; Gustavo Ferreira de Oliveira ${ }^{5}$. \\ ${ }^{1}$ Universidade Federal do Sul e Sudeste do Pará (UNIFESSPA), Marabá, Pará, Brasil, kalynerosa_agro@hotmail.com \\ 2 UNIFESSPA, Marabá, Pará, Brasil, elainyamaral@gmail.com \\ 3 UNIFESSPA, Marabá, Pará, Brasil, andressa.nunesoliveira@gmail.com \\ ${ }^{4}$ UNIFESSPA, Marabá, Pará, Brasil, andreahentz@unifesspa.edu.br \\ ${ }^{5}$ UNIFESSPA, Marabá, Pará, Brasil, gf.oliveira90@hotmail.com
}

RESUMO: O objetivo deste trabalho, foi avaliar os componentes químicos do solo e seus principais indicadores, a fim de identificar o potencial produtivo e a capacidade de suprir as necessidades de seus sistemas no lote 31 do Projeto do Assentamento Veneza no Sudeste do Pará. O trabalho foi realizado no projeto de Assentamento Veneza no lote 31, Município de São Domingos do Araguaia-PA. Para as análises de solo foram coletadas amostras de solos das áreas de pastos 1 e 2, e área de capoeira que se localizavam próximo ao pasto 3. Para caracterização dos indicadores químicos do solo foram retiradas 15 amostras simples em cada área, as amostras simples foram reunidas e misturadas, formando uma amostra composta. Após homogeneização, as mesmas foram encaminhas para o laboratório, para realização das análises químicas de interesse. As análises feitas compreenderam as determinações de pH em água e dos teores de $\mathrm{Al}, \mathrm{Ca}, \mathrm{Mg}, \mathrm{H}+\mathrm{Al}$, bem como os cálculos pertinentes para a obtenção dos índices, SB e V\%. pH do pasto 1 e da área de capoeira apresentaram valores de 5,7 e 5,3 respectivamente, logo não apresentam diferenças entre suas amostras, ambos são considerados agronomicamente de acidez média já que apresentam pH entre 5,1 - 6,0. O pasto 2 o pH apresentou acidez elevada em comparação com as outras áreas avaliadas com 4,9. A área do pasto 2 foi a que apresentou menores valores da qualidade química, além de ter acidez elevada obtém o menor teor de matéria orgânica.

PALAVRAS-CHAVE: Pastagem, Acidez do solo, Manejo

\section{CHEMICAL SOIL INDICATORS UNDER DIFFERENT USES AND MANAGEMENT IN LOT 31 OF THE VENICE SETTLEMENT PROJECT IN SOUTHEASTERN PARÁ}

ABSTRACT: The objective of this work was to evaluate the soil chemical components and their main indicators in order to identify the productive potential and the capacity to meet the needs of their systems in lot 31 of the Venice Settlement Project in the Southeast of Pará. Carried out in the project of Settlement Venice in lot 31, Municipality of São Domingos do Araguaia-PA. Soil samples were collected from soils of pasture areas 1 and 2, and capoeira area, which were located near pasture 3. To characterize soil chemical indicators, 15 simple 
samples were collected in each area; Collected and mixed, forming a composite sample. After homogenization, they were sent to the laboratory to perform the chemical analyzes of interest. The analyzes included $\mathrm{pH}$, water and $\mathrm{Al}, \mathrm{Ca}, \mathrm{Mg}, \mathrm{H}+\mathrm{Al}$, as well as the relevant calculations to obtain the indexes, SB and $\mathrm{V} \%$. $\mathrm{PH}$ of pasture 1 and capoeira area presented values of 5.7 and 5.3 respectively, so they do not present differences between their samples, both are considered agronomically of medium acidity since they have $\mathrm{pH}$ between 5.1 - 6.0. Pasture $2 \mathrm{pH}$ had high acidity in comparison to the other areas evaluated with 4.9. The area of pasture 2 presented the lowest values of the chemical quality, besides having high acidity, it obtained the lowest content of organic matter.

KEYWORDS: Pasture, soil acidity, management

\section{INDICADORES QUIIMICOS DEL SUELO BAJO DIFERENTES USOS Y MANEJO EN EL LOTE 31 DEL PROYECTO DE ASENTAMIENTO VENECIA EN EL SUDESTE DE PARÁ}

RESUMEN: El objetivo de este trabajo, fue evaluar los componentes químicos del suelo y sus principales indicadores, a fin de identificar el potencial productivo y la capacidad de suplir las necesidades de sus sistemas en el lote 31 del Proyecto del Asentamiento Venecia en el Sudeste de Pará. el trabajo fue realizado en el proyecto de Asentamiento Venecia en el lote 31, Municipio de São Domingos do Araguaia-PA. Para los análisis de suelo se recogieron muestras de suelos de las áreas de pastos 1 y 2 y área de capoeira que se ubicaban cerca del pasto 3. Para caracterización de los indicadores químicos del suelo se tomaron 15 muestras simples en cada área, reunidas y mezcladas, formando una muestra compuesta. Después de la homogeneización, las mismas fueron encaminas al laboratorio, para realizar los análisis químicos de interés. Los análisis realizados incluyeron las determinaciones de $\mathrm{pH}$ en agua y de los contenidos de $\mathrm{Al}, \mathrm{Ca}, \mathrm{Mg}, \mathrm{H}+\mathrm{Al}$, así como los cálculos pertinentes para la obtención de los índices, SB y V\%. El pH del pasto 1 y del área de capoeira presentaron valores de 5,7 y 5,3 respectivamente, luego no presentan diferencias entre sus muestras, ambos se consideran agronomicamente de acidez media ya que presentan $\mathrm{pH}$ entre 5,1 - 6,0. El pastoreo 2 el pH presentó acidez elevada en comparación con las otras áreas evaluadas con 4,9. El área del pasto 2 fue la que presentó menores valores de la calidad química, además de tener acidez elevada obtiene el menor contenido de materia orgánica.

PALABRAS CLAVE: Pasto, Acidez del suelo, Manejo

As práticas de manejo do solo provocam alterações nos seus atributos físicos, químicos e biológicos, significando perda de qualidade e afetando a sustentabilidade ambiental e econômica da atividade agrícola (NIERO et al., 2010). 
Por outro lado, a boa qualidade desses atributos propicia condições adequadas para o crescimento e o desenvolvimento das plantas e para a manutenção da diversidade de organismos que habitam o solo (DORAN; PARKIN, 1994).

Segundo Trindade et al. (2011) os solos amazônicos são conhecidos pela sua baixa fertilidade natural, que além da elevada acidez, apresenta baixos teores de fósforo na forma disponível pelas plantas. Entre os fatores que propiciam a baixa produtividade das culturas nessa região, a acidez do solo, expressa por baixos valores de $\mathrm{pH}$ e alta concentração de Al, além de baixos teores de Ca e Mg, é um dos mais importantes a serem corrigidos para a garantia de rendimento econômico das culturas (GAMA et al., 2007).

Vários estudos têm mostrado a importância das características químicas dos solos na produção das culturas e as alterações ocorridas nessas características em função dos sistemas de uso e manejo (LONGO; ESPÍNDOLA, 2000). OS indicadores químicos são, normalmente, agrupados em variáveis relacionadas com o teor de matéria orgânica do solo, acidez do solo, o conteúdo de nutrientes e determinadas relações como a saturação de bases (V\%) e de alumínio (ARAÚJO et al., 2012).

No solo os atributos físicos, químicos e biológicos estão interrelacionados, os quais controlam os processos e os aspectos à sua variação no tempo e no espaço (CARNEIRO et al., 2009). Sendo que, o uso constante desses solos com práticas agrícolas que não se preocupa com a reposição dos nutrientes, tem resultado em solos com estágios avançados de degradação. Portanto, a avaliação conjunta desses atributos é de grande importância para o manejo correto do solo e das culturas em geral.

No sudeste do Pará em estabelecimentos agrícolas familiares é comum o corte da floresta nativa ou capoeira para a implantação de pastagens ou plantio de culturas anuais como: mandioca (Manihot esculenta), feijão (Vigna unguiculata) e milho (Zea mays). Contudo, segundo Araújo et al., (2004) o uso sucessivo dessas áreas tem levado ao empobrecimento químico do solo e surgimento de plantas 
espontâneas, pragas e doenças, as quais são deixadas em pousio em ciclos que variam de 5 a 10 anos.

De acordo com Araújo et al. (2007) o uso sustentável dos recursos naturais, como o solo e a água tem sido um tema de crescente relevância devido ao aumento das atividades antrópicas. Contudo, práticas de manejo sustentável são observadas na agricultura familiar como a diversificação de cultivos e o menor uso de insumos químicos, entre outros.

Diante disso, o objetivo deste trabalho, foi avaliar os componentes químicos do solo e seus principais indicadores, a fim de identificar o potencial produtivo e a capacidade de suprir as necessidades de seus sistemas no lote 31 do Projeto de Assentamento Veneza no Sudeste do Pará.

trabalho foi realizado no Projeto de Assentamento Veneza no lote 31, Município de São Domingos do Araguaia no estado do Pará, o local possui uma área de 28.5030 ha. $\bigcirc$ assentamento localiza - se cerca de $45 \mathrm{~km}$ do perímetro urbano de Marabá sudeste Paraense.
O Clima segundo a classificação de Koppen é de tipo AW, menos chuvoso entre os meses de abril a outubro e chuvoso entre novembro a março, com índice pluviométrico médio anual em torno de 1.600 mm e umidade relativa do ar em torno de 76\% a 80\% (ALMEIDA, 2007). O relevo do assentamento apresenta-se plano (75\%) e suavemente ondulado (25\%) (INCRA, 2014).

Nossa área de estudo foram as áreas de pasto 1 e pasto 2 e uma área de capoeira, sendo que as áreas de pastagem são constituídas de duas variedades de gramíneas. O pasto1 é constituído das variedades Mombaça (Panicum maximum) e Massai (Panicum híbrido vr. Massal), o pasto 2 encontramse as variedades Quicuia (Pennisetum clandestinum) e Mombaça. A área de capoeira está sendo mantida há pelos 10 anos pela família de agricultores. Para as análises de solo foram coletadas amostras de solos das áreas de pastos 1 e 2, e da área de capoeira.

Para caracterização dos indicadores químicos do solo foram retiradas 15 amostras simples em cada área, conforme instruções elaboradas pela Empresa 
Brasileira de Pesquisa Agropecuária (EMBRAPA, 1996), utilizando um trado holandês. As amostras simples foram reunidas e misturadas em um balde plástico limpo, formando uma amostra composta. Após homogeneização, retirou-se aproximadamente $500 \mathrm{~g}$ de solo de cada área, transferindo-a para um saco plástico identificado pelo nome correspondente a área e suas informações complementares. As amostras obtidas foram encaminhadas para o FULLIN Laboratório de Análise Agronômica e Ambiental LTDA, em Linhares, ES, para realização das análises químicas de interesse. As análises feitas compreenderam as determinações de pH em água e dos teores de $\mathrm{Al}, \mathrm{Ca}, \mathrm{Mg}, \mathrm{H}+\mathrm{Al}$, bem como os cálculos pertinentes para a obtenção dos índices, SB e V\%.

Os resultados das análises químicas do solo, das três áreas estão representados na tabela $1.0 \mathrm{pH}$ do pasto 1 e da área de capoeira apresentaram valores de 5,7 e 5,3 respectivamente, logo não apresentam diferenças expressivas entre suas amostras, ambos são considerados agronomicamente de acidez média já que apresentam pH entre 5,1 - 6,0. Os solos agrícolas brasileiros, na maioria, apresentam média a alta acidez $\left(\mathrm{pH} \quad \mathrm{H}_{2} \mathrm{O} \quad<5,5\right)$ que traz como consequência, a baixa produtividade das culturas (VELOSO et al. 1992). O pasto 2 o pH apresentou acidez elevada em comparação com as outras áreas avaliadas com 4,9.

Tabela 1. Características químicas do solo na camada arável $(0-20 \mathrm{~cm})$ nas três áreas.

\begin{tabular}{|c|c|c|c|c|c|c|}
\hline Características & Valor & Interpretação & Valor & Interpretação & Valor & Interpretação \\
\hline & ---------- & Pasto 1 -------- & --------- & Pasto 2 --------- & ------- & Capoeira ------ \\
\hline pH em água & 5,7 & Acidez Média & 4,9 & Acidez Elevada & 5,3 & Acidez Média \\
\hline $\mathrm{Al}^{3+}\left(\mathrm{cmol}_{\mathrm{c}} / \mathrm{dm}^{3}\right)$ & 0,0 & Baixo & 0,6 & Médio & 0,3 & Baixo \\
\hline $\mathrm{Ca}^{2+}\left(\mathrm{cmol}_{\mathrm{c}} / \mathrm{dm}^{3}\right)$ & 2,2 & Médio & 1,1 & Baixo & 1,2 & Baixo \\
\hline $\mathrm{Mg}^{2+}\left(\mathrm{cmol}_{\mathrm{c}} / \mathrm{dm}^{3}\right)$ & 0,5 & Baixo & 0,2 & Baixo & 0,6 & Médio \\
\hline $\mathrm{SB}\left(\mathrm{cmol}_{\mathrm{c}} / \mathrm{dm}^{3}\right)$ & 3,3 & Media & 1,8 & Médio & 2,2 & Médio \\
\hline $\left.\mathrm{Al}+\mathrm{H} \mathrm{cmol} c / \mathrm{dm}^{3}\right)$ & 2,4 & Baixa & 3,1 & Médio & 3,1 & Media \\
\hline V (\%) & 57,7 & Médio & 36,4 & Baixa & 41,8 & Baixa \\
\hline
\end{tabular}

O pasto 1 e a área de capoeira apresentaram valores baixos de $\mathrm{Al}^{3+}$ enquanto que o pasto 2 foi tido como médio. Os valores de $\mathrm{Ca}^{2+}$ para o pasto 2, 
foi de 1,1 e para a área de capoeira 1,2 (Tabela 1), tendo em vista que ambos estão abaixo dos valores de referência para esse solo segundo a Fullin (2012) (< 1,5 cmolc $\left./ \mathrm{dm}^{3}\right)$. O cálcio geralmente encontra-se em baixa concentração nos solos ácidos, que são típicos do território brasileiro, tal nutriente participa nas funções estruturais, osmóticas e de mensageiro citoplasmático (WHITE, 1998).

O magnésio obteve concentração de 0,2 cmolc. $\mathrm{dm}^{3}$ no pasto 2, resultados semelhantes foram encontrados por Dotta (et al. 2014), em áreas de pastagens com diferentes estágios de degradação obteve concentração média de aproximadamente $0,3 \mathrm{cmolc} / \mathrm{dm}^{3}$. O pasto 1 também obteve concentração baixa de magnésio. Caetano (et al. 2013) salientam que os valores relativamente baixos dos nutrientes podem ser explicados pela falta de manejo adequado durante os anos. Carneiro (et al. 2009) afirmam que a calagem, antes da implementação da cultura, poderia contribuir para um aumento no $\mathrm{pH}$ consequentemente uma diminuição do teor de alumínio além do aumento nos teores de cálcio e magnésio.
A Soma de Base das áreas analisadas não apresentou diferença significativa entre elas, mesmo sendo numericamente distintos. O cálculo para obter-se a soma de bases leva em conta os teores de $\mathrm{Ca}^{2+}$ $\mathrm{Mg}^{2+}$ e K. O pasto 1 apresentou menor valor para acidez potencial, com 2,4 $\mathrm{cmolc} / \mathrm{dm}^{3}$.

O pasto 2 e a área de capoeira apresentaram menor saturação por base com 36,4 e 41,8 respectivamente. Segundo Tomé Júnior (1997), a saturação por bases é um excelente indicativo das condições gerais de fertilidade do solo, pois é a partir de seus percentuais que são definidos o caráter eutrófico e distrófico do solo. A maioria das culturas apresenta boa produtividade quando no solo é obtido valor V\% entre 50 e $80 \%$ e valor de pH entre 6,0 e 6,5 (RONQUIM 2010).

A área de pasto 2 apresentou menor valor de Fósforo 3,0 mg/ $\mathrm{dm}^{3}$. Já o pasto 1 obteve melhor resultado com 15 mg/ $\mathrm{dm}^{3}$, esse resultado pode estar relacionado com o manejo realizado na área como o roço, meses antes da análise de solo. Para Rheinheimer et al. (2008) o uso da roçada, uma das práticas de melhoramento das pastagens, causa 
incremento nos teores de P microbiano, especialmente quando é adicionado $P$ inorgânico concomitantemente. (Tabela 2). Os solos tropicais se caracterizam pelo elevado grau de intemperismo e pelos baixos teores de fósforo na forma disponível as plantas (ROCHA et al., 2005). O fósforo é, frequentemente, o fator que restringe 0 crescimento de plantas (HINSINGER, 2001).

Tabela 2. Características químicas do solo na camada arável $(0-20 \mathrm{~cm})$ nas três áreas.

\begin{tabular}{|c|c|c|c|c|c|c|}
\hline Características & Valor & Interpretação & Valor & Interpretação & Valor & Interpretação \\
\hline & ----- & $\begin{array}{l}\text { Pasto } 1 \text {------- } \\
-\end{array}$ & ------ & Pasto 2 -------- & ------- & apoeira ------- \\
\hline$P\left(\mathrm{mg} / \mathrm{dm}^{3}\right)$ & 15 & Médio & 3,0 & Baixo & 5,0 & Baixo \\
\hline$K\left(\mathrm{mg} / \mathrm{dm}^{3}\right)$ & 130 & Médio & 104 & Médio & 87 & Médio \\
\hline $\mathrm{Na}^{+}\left(\mathrm{mg} / \mathrm{dm}^{3}\right)$ & 54 & Médio & 48 & Médio & 46 & Médio \\
\hline$(\mathrm{MO})^{1 /}$ & 1,6 & Médio & 1,2 & Baixo & 1,6 & Médio \\
\hline
\end{tabular}

1/Oxidação: Na2Cr2O7 2H2O + 4 mol/L H2SO4 10 mol/L.

Os indicadores $\mathrm{K}^{+}$e $\mathrm{Na}^{+}$são considerados médios para todas as áreas analisadas. A matéria orgânica não apresentou diferenças entre as áreas de pasto 1 e a área de capoeira. Um dos fatores importantes que contribui para o aumento da matéria orgânica no solo sob pastagem é a incorporação de matéria orgânica oriunda do sistema radicular, uma vez que após o corte da planta verifica-se a morte de até 50\% do sistema radicular (CECATO et al., 2001).

O uso e o manejo mal-empregado podem gerar mudanças nos componentes químicos do solo e alterar seu potencial produtivo. Essas mudanças dão origem a degradação da área, caracterizada pela diminuição de nutrientes benéficos ao sistema e a pouca capacidade que essas áreas têm de suprir suas necessidades produtivos. Com isso, o pasto 2 foi o que apresentou menores valores da qualidade química, além de ter acidez elevada apresentou o menor teor de matéria orgânica. Já a área de pasto 1 foi o que obteve os melhores parâmetros analisados da qualidade química.

\section{REFERÊNCIAS}

ALMEIDA, M. F. Caracterização Agrometeorológica do Município de Marabá/PA. Trabalho de Conclusão de Curso - Universidade Federal do Pará, Colegiado de Ciências Agrárias, Marabá, 
2007.

ARAÚJO, E. A.; LANI, J. L.; AMARAL, E. F.; GUERRA, A. Uso da terra e propriedades físicas e químicas de Argissolo Amarelo distrófico na Amazônia Ocidental. Revista Brasileira de Ciência do Solo, v. 28, n. 2, 2004.

ARAÚJO, E. A. de; KER, J. C.; NEVES, J. C. L. LANI, J. L. Qualidade do solo: conceitos, indicadores e avaliação. Revista Brasileira de Tecnologia Aplicada nas Ciências Agrárias, Guarapuava- PR, v.5, n.1, p.187206, 2012.

ARAÚJO, R.; GOEDERT, W. J.; LACERDA, M. P. C. Qualidade de um solo sob diferentes usos e sob cerrado nativo. Revista Brasileira de Ciência do solo, v. 31, n. 5, 2007.

CAETANO, J. O.; VERGINASSI, A.; ASSIS, P. C. R.; CARNEIRO, M. A. C.; PAULINO, H. B. Indicadores de qualidade de um Latossolo Vermelho sob diferentes sistemas de uso e manejo. GI. SciTechnol, v. 6, n. 1, p.2639, 2013.

CARNEIRO, M. A. C.; SOUZA, E. D.; REIS, E. F.; PEREIRA, H. S.; AZEVEDO, W. R. Atributos físicos, químicos e biológicos de solo de cerrado sob diferentes sistemas de uso e manejo. Revista Brasileira de Ciência do Solo, v. 33, n. 1, 2009.

CECATO, U.; CANO, C. C. P.; BORTOLO, M.; HERLING, V. R.; CANTO, M. W. do; CASTRO, C. R. Teores de carboidratos não estruturais, nitrogênio total e peso de raízes em coastcross-1 (Cynodon dactylon (L.) pastejado por ovinos. Revista Brasileira de Zootecnia, v. 30, n. 2, p. 644-50, 2001.
DORAN, J. W.; PARKIN, T. B. Defining and assessing soil quality. In: DORAN, J. W. et al. (Eds.). Defining soil quality for a sustainable environment. Madison: SSSA, 1994. v. 1, cap. 1, p. 3-21.

DOTTA, J. C.; SANTOS, A. C.; ARAÚJO, A. S.; SOARES, C. V.; RODRIGUES, M. O. D. Química do solo em pastagem com três níveis de degradação em região de ecotono cerrado- Amazônia. Sociedade Brasileira de Ciência do Solo, Núcleo Regional Amazônia Oriental, Anais... Trabalhos completos, Gurupi-TO, 2014.

EMBRAPA. Recomendações técnicas para o cultivo do milho. Brasília: EMBRAPA-SPI, 1996. 204p.

FULIM, Laboratório de Análises Agronômica. Valores de referências. Análises de solo. Vitória, Espírito Santo, 2012.

GAMA， J.R.F.N.; CARVALHO, E.J.M.; RODRIGUES, T.E. \& VALENTE, M.A. Solos do Estado do Pará. In: CRAVO, M.S.; VIÉGAS, I.J.M. \& BRASIL, E.C., eds. Recomendações de adubação e calagem para o estado do Pará. Belém, Embrapa Amazônia Oriental, 2007. p.19-29.

HINSINGER, P. Biology availability of soil inorganic $P$ in the rhizosphere as affected by root-induced chemical changes: A review. Plant and Soil, v. 237, p. 173-195, 2001.

INCRA. Memorial de desenvolvimento. Pg única. Marabá-Pá, 2014.

LONGO, R.M.; ESPÍNDOLA, C.R. 2000. Alterações em características químicas de solos da região amazônica pela introdução de pastagens. Acta 
Amazonica, n. 30, p. 71-80.

NIERO, L. A.; FALCI, S. C., MARQUES, C. R.; CLERICI, M. Avaliações visuais como índice de qualidade do solo e sua validação por análises físicas e químicas em um Latossolo Vermelho distroférrico com usos e manejos distintos. Revista Brasileira de Ciência do Solo, Viçosa, v. 34, n. 4, p. $1271-1282,2010$.

RHEINHEIMER, D.S.; MARTINAZZO, R.; GATIBONI, L.C.; KAMINSKI, J.; SILVA L.S. Amplitude no fósforo microbiano em um Argissolo em pastagem nativa submetida à roçada e à introdução de espécies forrageiras com fertilização fosfatada em diferentes épocas. Acta Sci. Agron. Maringá, v. 30, p. 561-567, 2008.

ROCHA, A. T.; DUDA, G. P.; NASCIMENTO, C. W. A.; RIBEIRO, M. R. Fracionamento de fósforo e avaliação de extratores de P-disponível em solos da itha de Fernando de Noronha. Revista Brasileira de Engenharia Agrícola e Ambiental, v. 9, n. 2, p. 178-184, 2005.

RONQUIM, C. S. Conceitos de fertilidade do solo e manejo adequado para as regiões tropicais. Campinas- SP: Embrapa Monitoramento por Satélite. 2010, 26 p. (Boletim de Pesquisa e Desenvolvimento, 8).

TOMÉ JÚNIOR J. B. Manual para a interpretação de análise de solo. Guaiba: Agropecuária, 1997, p. 59-87.

TRINDADE, E. F. S.; KATO, O. R.; CARVALHO E. J. M.; SERAFIM E. C. S. Disponibilidade de fósforo em solos manejados com e sem queima no nordeste paraense. Embrapa Amazônia Oriental-Artigo em periódico indexado
(ALICE), Belém, v. 6, n. 12. 2011.

VELOSO, C.A.C.; BORGES, A.L.; MUNIZ A.S.; VEIGAI.A. de J.M. S. Efeito de diferentes materiais no $\mathrm{pH}$ do solo. Scientia agricola, Piracicaba-SP 1992.

WHITE, P. J. Calcium channels in the plasma membrane of roots cells. Annals of Botany, v. 81, p. 173-183, 1998. 